\title{
0438. Effects of positive end-expiratory pressure (PEEP) on the pattern of breathing during neurally adjusted ventilatory assist. A pilot study in a mild ards porcine model
}

\author{
M Pellegrini ${ }^{1,2^{*}}$, G Perchiazzi 1 , A Ronéus ${ }^{2}$, I Andersson ${ }^{3}$, T Fiore ${ }^{1}$, A Larsson $^{2}$, G Hedenstierna $^{2}$ \\ From ESICM LIVES 2014 \\ Barcelona, Spain. 27 September - 1 October 2014
}

\section{Introduction}

Spontaneous breathing during mechanical ventilation is still controversial. It is well known that incongruous patterns of mechanical ventilation can trigger or exacerbate lung injury. NAVA is a mode of mechanical ventilation that delivers ventilatory assist in proportion to the Electrical activity of the Diaphragm (EDi), which mirrors the performance of the whole respiratory system. However during NAVA, the effects of PEEP on the EDi signal, respiratory rate and breathing heterogeneity are unknown.

\section{Objectives}

The purpose of the present pilot study was to evaluate the effects of PEEP on the ventilatory pattern during NAVA support in a porcine model of mild ARDS.

\section{Methods}

Three anesthetized, tracheostomized and spontaneous breathing piglets, underwent NAVA ventilation. Mild ARDS was achieved by repeated lung lavages and bronchial aspiration (targeting a $\mathrm{PaO}_{2} / \mathrm{FiO}_{2}$ ratio of 200). Each animal was ventilated with four different supports: Optimal NAVA (NAVA ${ }_{\mathrm{OPT}}$, defined by using Brander et al. method ${ }^{1}$ ), Low NAVA (NAVA LOw $_{\text {defined as }}$ NAVA $_{\mathrm{OPT}}-20 \%$ ), High NAVA $\left(\mathrm{NAVA}_{\mathrm{HI}}\right.$ defined as NAVA $\left._{\mathrm{OPT}}+20 \%\right)$ and unsupported breathing $\left(\mathrm{NAVA}_{\text {zero }}\right.$ defined as NAVA of $0 \mathrm{cmH}_{2} \mathrm{O} / \mu \mathrm{V}$ ). During each pattern of ventilation, a stepwise change in PEEP was applied, first incrementing PEEP from 0 to $15 \mathrm{cmH}_{2} \mathrm{O}$ in steps of $3 \mathrm{cmH}_{2} \mathrm{O}$; then decrementing it from 15 to $0 \mathrm{cmH}_{2} \mathrm{O}$

'Università di Bari Aldo Moro, Dept. of Emergency and Organ Transplant, Bari, Italy

Full list of author information is available at the end of the article with the same steps. During each step, after a steady state was reached, the main hemodynamic and respiratory parameters were recorded and a breath-by-breath analysis of flow, airway pressures and EDi waves, was performed by using custom made Matlab (The Mathworks, Natick, USA) codes. We defined as index of breathing pattern heterogeneity (BPH), the percentage of breaths whose maximum EDi (EDI $\max$ ) exceeds by 2 standard deviations the mean of $\mathrm{EDI}_{\max }\left(\mathrm{EDI}_{\max }\right.$, mean $)$; minimum EDi (EDI $\left.I_{\text {min, mean }}\right)$ is the mean of lowest EDIs reached in a breath sample. Statistical analysis was performed by testing significant differences of respiratory rate $(\mathrm{RR}), \mathrm{EDI}_{\text {max }}$, mean, $\mathrm{EDI}_{\text {min, mean }}$ and $\mathrm{BPH}$ at each applied PEEP using the Student's T test $(\alpha=0.05)$ at the various NAVA levels.

\section{Results}

RR was inversely related to applied PEEP. Increasing PEEP, EDI max $_{\text {, mean }}$ increases while $\mathrm{EDI}_{\text {min, mean }}$ decreases. Breathing pattern heterogeneity did not change in relation to PEEP variation.

\section{Conclusions}

The application of PEEP during spontaneous breathing in a model of mild ARDS influenced the ventilatory pattern, i.e., the respiratory rate, the diaphragmatic tonic $\left(\mathrm{EDI}_{\mathrm{min}}\right.$, mean $)$ and the phasic contraction $\left(\mathrm{EDI}_{\text {max, mean }}\right)$. If these effects are valid in patients, they will be clinically important when using NAVA as a weaning mode.

\section{Grant acknowledgment}

The School of Anesthesia and Intensive Care of Medicine, Bari University; The Swedish heart and lung foundation. 


\section{Authors' details}

${ }^{1}$ Università di Bari Aldo Moro, Dept. of Emergency and Organ Transplant,

Bari, Italy. ${ }^{2}$ Uppsala University, Dept. of Surgical Sciences, Uppsala, Sweden.

${ }^{3}$ Kalmar Hospital, Dept. of Anesthesia and Intensive Care, Kalmar, Sweden.

Published: 26 September 2014

\section{Reference}

1. Brander L, et al: Intensive Care Med 2009, 35:1979-89.

doi:10.1186/2197-425X-2-S1-P28

Cite this article as: Pellegrini et al: 0438. Effects of positive end-

expiratory pressure (PEEP) on the pattern of breathing during neurally

adjusted ventilatory assist. A pilot study in a mild ards porcine model.

Intensive Care Medicine Experimental 2014 2(Suppl 1):P28.

\section{Submit your manuscript to a SpringerOpen ${ }^{\circ}$ journal and benefit from:}

- Convenient online submission

- Rigorous peer review

- Immediate publication on acceptance

- Open access: articles freely available online

- High visibility within the field

- Retaining the copyright to your article

Submit your next manuscript at $\gg$ springeropen.com 